\title{
Highly selective deethylation of rhodamine B: Adsorption and photooxidation pathways of the dye on the $\mathrm{TiO}_{2} / \mathrm{SiO}_{2}$ composite photocatalyst
}

\author{
Feng Chen, ${ }^{1}$ Jincai Zhao, ${ }^{2}$ and Hisao Hidaka ${ }^{1, \dagger}$ \\ ${ }^{1}$ Frontier Research Center for the Global Environment Protection, Meisei University, 2-1-1 Hodukubo, \\ Hino, Tokyo 191-8506, Japan \\ 2 The Laboratory of Photochemistry, Center for Molecular Science, Institute of Chemistry, \\ Chinese Academy of Sciences, Beijing 100080, China
}

\begin{abstract}
The photocatalytic degradation of Rhodamine $\mathrm{B}(\mathrm{RhB})$ with $\mathrm{TiO}_{2}$ and $\mathrm{TiO}_{2} / \mathrm{SiO}_{2}$ in the aqueous dispersion was investigated under both the visible light $(\lambda>480 \mathrm{~nm})$ and UV irradiation. The detailed photocatalytic oxidative process of $\mathrm{RhB}$ under these different conditions was revealed by measurement of the isoelectric points of the catalysts, UV-VIS spectra, HPLC and LC-MS. RhB adsorbs on the surface of $\mathrm{TiO}_{2} / \mathrm{SiO}_{2}$ particles by the positively-charged diethylamino group while, in the case of net $\mathrm{TiO}_{2}$, it adsorbs through the negatively-charged carboxyl group under the experimental conditions $(\mathrm{pH} \sim 4.3)$. In the $\mathrm{RhB}^{-\mathrm{TiO}_{2}} / \mathrm{SiO}_{2}$ system, RhB firstly underwent a highly selective stepwise deethylation process before the destruction of the chromophore structure under visible light irradiation. The average yield of the every deethylation step was higher than $86 \%$. It is confirmed that visible light-induced photocatalytic degradation of dye proceeds on the surface of catalysts rather than in the bulk solution and active oxygen species preferentially attack the molecular portion that connects directly to the surface of catalysts. This work provides a possibility for the modification of the surface characteristics of $\mathrm{TiO}_{2}$ to adsorb effectively the special colored organic molecules in selective mode for selective modification or deeply extent photooxidation.
\end{abstract}

\section{INTRODUCTION}

Photocatalytic oxidation technology based on $\mathrm{TiO}_{2}$ has been proved effectively for the degradation and mineralization almost all of the organic compounds, and is regarded as one of the most prospectively environmental cleaning technologies. The photocatalytic process is initialed by UV irradiation that induces the band-band excitation of $\mathrm{TiO}_{2}$ to form conductive electrons and valence holes [1-3]. Then the electrons and holes react with preadsorbed $\mathrm{H}_{2} \mathrm{O}, \mathrm{HO}^{-}$and $\mathrm{O}_{2}$ to produce active oxygen species, which degrade and even entirely mineralize an organic compound. The radiation can directly excite the $\mathrm{TiO}_{2}$ nanoparticles should have an energy higher than $3.2 \mathrm{eV}(\lambda<385 \mathrm{~nm})$, which only contains $3-5 \%$ radiation of the solar light that reaches the earth surface. Recently, extensive research works also involved in the utilization of visible light to the organic pollutant photocatalytic degradation to extend the utilizable efficiency of solar light [4-11]. Many of the research works are focused on dye sensitized photocatalytic technology [4-9] while some of them successfully bathochromic shift the photoresponse of the catalyst by the modifying the $\mathrm{TiO}_{2}[10,11]$. In the dye-sensitized photocatalytic technology, dyes absorb visible light and transfer the LUMO electrons of excited

\footnotetext{
† E-mail: hidaka@epfc.meisei-u.ac.jp
}

dyes to the conductive band of $\mathrm{TiO}_{2}$, the conductive band electrons further react with preadosrbed oxygen to generate active oxygen species which would lead to the degradation of the organics substrates. This technology has strong photoresponse to the visible light and further can be easily controlled by selecting the special dyes and irradiation wavelength. Therefore, dye sensitization technologies have been widely applied in either environmental cleanings [5-7] or solar cells devices [12, 13].

The effect of adsorption of organics substrate on the surface of $\mathrm{TiO}_{2}$ has become a focus of attention since the early study of the photocatalytic oxidation. Both the reaction mechanisms, under either UV or visible irradiation, suggest that preliminary adsorption of organic substrate on the $\mathrm{TiO}_{2}$ surface exhibits an advantage for high efficient oxidation. Many inert adsorbents, such as activated carbon [14], silica gel [15-17], and zeolites [18] have been used as a support for $\mathrm{TiO}_{2}$ supporting to concentrate the target molecules on the surface of catalysts and thus enhanced the photocatalytic degradation rate relative to the net $\mathrm{TiO}_{2}$ catalyst. On the other hand, the adsorption modes of the organics substrate on the surface of $\mathrm{TiO}_{2}$ have been found playing an important role in the photodegradation pathways of organics [19, 20]. For example, we have examined the different visible light photocatalytic 
oxidation pathways of Sulforhodamine B (SRB) through controlling its adsorption modes on the surface of $\mathrm{TiO}_{2}$ by addition of surfactants [19]. However, there are some defects in the way to control the adsorption mode and degradation of organics by extra addition of surfactants. There are two main disadvantages: (1) The existence of a great number of extra additional organic compounds induces the trapping of active oxidation species, which greatly lowers the rate and photoefficiency of the photocatalytic reaction. (2) Additional organic compounds enhances the difficulties and complicacy to analyze and separate the photocatalytic oxidation products (and intermediates) of the target compound. These problems make it unfavorable for either the environmental cleaning application which is based on the entirely mineralization of target molecules, or detecting and obtaining the special products from the target molecules based on photocatalytic selective synthesis.

In this work, $\mathrm{SiO}_{2}$ was mingled into the $\mathrm{TiO}_{2}$ nanoparticles for preparing the composite photocatalysts to control the surface characteristic of the catalysts, and further to control the adsorption modes of target molecules $(\mathrm{RhB})$ on the surface of the photocatalysts. The photocatalytic oxidation of Rhodamine B in the different adsorption modes was examined under both the UV and visible light irradiation. It is found that combination of the $\mathrm{SiO}_{2}$ into $\mathrm{TiO}_{2}$ can change the photooxidation pathways of the RhB molecules under visible light irradiation. Especially, the deethylation process of the dye $(\mathrm{RhB})$ was greatly enhanced. This provides a potential approach for utilization of visible light-induced photocatalysis of $\mathrm{TiO}_{2}$ to molecular design and synthesis by transforming the special group of the target molecules, besides the environmental cleaning application.

\section{EXPERIMENTAL}

2.1. Materials. $\mathrm{P}-25 \mathrm{TiO}_{2}$ (ca. $87 \%$ anatase, $13 \%$ rutile; BET area ca. $50 \mathrm{~m}^{2} \mathrm{~g}^{-1}$ ) was supplied by Degussa Co. The dye Rhodamine B (RhB) was bought from Wako pure chemical industries Ltd.. Titanium tetraisopropoxide and silicon tetraethoxide were of analytical reagent grade quality. Deionized water was used throughout this work. The $\mathrm{pH}$ value of the solution was adjusted with $\mathrm{HCl}$ and $\mathrm{NaOH}$ unless specially clarified. The structure of the RhB molecule is illustrated below.<smiles>CCCCCCCCCN(CCC)c1ccc2c(-c3ccccc3C(=O)O)c3ccc(=[N+](Cl)CC)cc-3oc2c1</smiles>

2.2. Photoreaction procedures and analytical methods. Aqueous solution of the $\mathrm{RhB}(45 \mathrm{ml}, 2 \times$ $10^{-5} \mathrm{M}$ ) was placed in the presence of photocatalyst in a $50 \mathrm{ml}$ Pyrex vessel. Prior to irradiation, the dispersion was magnetically stirred in the dark for about 1 hour to establish the adsorption/desorption equilibrium between the dye, photocatalyst and oxygen. Irradiation of the dispersions was carried out with a $500 \mathrm{~W}$ Xenon lamp in the visible irradiation case with $50 \mathrm{mg}$ photocatalyst and a $75 \mathrm{~W}$ mercury lamp in the UV irradiation case with $20 \mathrm{mg}$ photocatalyst. A cut-off filter was placed outside the light slit of xenon lamp for the complete removal of radiation below $480 \mathrm{~nm}$ for ensuring the dispersion was only irradiated by visible light. All the photocatalytic experiments were carried out at pH 4.3.

The $\zeta$-potential of photocatalysts was measured with an Otsuka ELS-800 electrophoretic light scattering spectrophotometer. Photocatalysts were dispersed in aqueous $\mathrm{NaCl}$ solution $(0.01 \mathrm{M})$ by sonication for the determining. All aqueous $\mathrm{NaCl}$ solution and deionized water used for the $\zeta$-potential measurement were prefiltered through a $0.1 \mu \mathrm{m}$ pore millifilter.

The temporal absorption of the filtered reaction solution was analyzed by UV-VIS spectroscopy using a JASCO V-560 UV-VIS spectrophotometer. The RhB and intermediates generated in the photooxidative process were analyzed with a JASCO liquid chromatograph (HPLC) equipped with a multiwavelength detector and Crestpak C18S column in the mixed eluent $\left(\mathrm{CH}_{3} \mathrm{CN}: \mathrm{H}_{2} \mathrm{O}=1: 1\right.$ by volume, $\mathrm{ClO}_{4}{ }^{-}=150 \mathrm{mM}, \mathrm{H}_{2} \mathrm{PO}_{4}=50 \mathrm{mM}, \mathrm{pH}=3.3$ ) and a Hewlett-Packard HP1100 series LC-MSD equipment in the mixed eluent of methanol and $\mathrm{H}_{2} \mathrm{O}(1: 1$ by volume) equipped with an Agilent Eclipse XDB-C8 column.

\subsection{Preparation of photocatalyst by sol-gel tech-}

nique. The required amount of titanium tetraisopropoxide (5.68 g) and silicon tetraethoxide (4.16 g) was diluted in $72 \mathrm{ml}$ ethanol and the solution was stirred for $30 \mathrm{~min}$ at room temperature. Then the solution was slowly added into $800 \mathrm{ml}$ deionized water that had been pre-adjusted with $\mathrm{HNO}_{3}$ solution to $\mathrm{pH}$ 1. The mixture was then kept in a water bath at $80^{\circ} \mathrm{C}$ for $8 \mathrm{~h}$ with stirring for the completely hydrolysis of titanium tetraisopropoxide and silicon tetraethoxide. At last, the gel was dried and calcined at $723 \mathrm{~K}$ for $2 \mathrm{~h}$ to obtain the $\mathrm{TiO}_{2} / \mathrm{SiO}_{2}$ composite photocatalyst. Net sol-gel $\mathrm{TiO}_{2}$ photocatalyst was prepared only using titanium tetraisopropoxide ethanol solution in the same procedure as the above $\mathrm{TiO}_{2} / \mathrm{SiO}_{2}$ sample. For distinguishing the sol-gel prepared $\mathrm{TiO}_{2}$ and $\mathrm{P}-25 \mathrm{TiO}_{2}$ in the paper, P-25 $\mathrm{TiO}_{2}$ was signed as P-25, sol-gel prepared $\mathrm{TiO}_{2}$ was signed as $\mathrm{TiO}_{2}(\mathrm{~S})$ and $\mathrm{TiO}_{2}$ means common titania which include both $\mathrm{P}-25$ and $\mathrm{TiO}_{2}(\mathrm{~S})$ in the hereinafter text. 


\section{RESULTS AND DISCUSSION}

3.1. $\zeta$-potential and isoelectric point of $\mathrm{TiO}_{2}$ and $\mathrm{TiO}_{2} / \mathrm{SiO}_{2}$. The $\mathrm{pH}$ value strongly influences the surface charge properties of metal-oxide particles in the aqueous dispersion. Normally, surface of the net $\mathrm{TiO}_{2}$ is positively charged in acid media and negatively charged in alkaline one with an isoelectric point of about pH $6 \sim 7$ [21]. Thus, adsorbates in the aqueous solution tend to adsorb on the surface of $\mathrm{TiO}_{2}$ by the negatively charged or electron abundant group in acidic solution because of the electrostatic interaction. The $\mathrm{pH}$ value of the reaction solutions under the experimental conditions was controlled at about 4.3, in which the surface of $\mathrm{TiO}_{2}$ was positively charged. The acid dissociation exponent of the carboxyl group of $\mathrm{RhB}$ was about $4.1 \pm 0.1$ as titrated by $\mathrm{NaOH}$ solution. Thus, under the experimental conditions, most of the carboxyl group of $\mathrm{RhB}$ was dissociated and negatively charged at $-\mathrm{COO}^{-}$state as shown in Scheme 1. Therefore, $\mathrm{RhB}$ tends to adsorb on the surface of $\mathrm{TiO}_{2}$ through the negatively charged carboxyl group. On the other hand, the isoelectric point of $\mathrm{SiO}_{2}$ is relative acidic (only about pH $1 \sim 2$ ) comparing with that of $\mathrm{TiO}_{2}$ in aqueous solution. Mingling $\mathrm{TiO}_{2}$ with $\mathrm{SiO}_{2}$ would most probably vary the $\mathrm{pH}$ value of the isoelectric point of the photocatalyst. Figure 1 displayed the $\zeta$-potential of $\mathrm{TiO}_{2}(\mathrm{~S})$ and $\mathrm{TiO}_{2} / \mathrm{SiO}_{2}$ under various $\mathrm{pH}$ values. The isoelectric point of the composite photocatalyst $\mathrm{TiO}_{2} / \mathrm{SiO}_{2}$ was remarkably lowered to $\mathrm{pH} 2.0$ while that of $\mathrm{TiO}_{2}(\mathrm{~S})$ was $\mathrm{pH}$ 6.2. Therefore, under the experimental condition ( $\mathrm{pH} 4.3$ ), the surface of $\mathrm{TiO}_{2} / \mathrm{SiO}_{2}$ was negatively charged. However, the net $\mathrm{TiO}_{2}$ is positively charged.

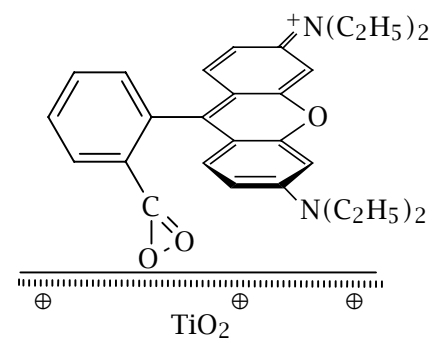

For $\mathrm{TiO}_{2}$ condition

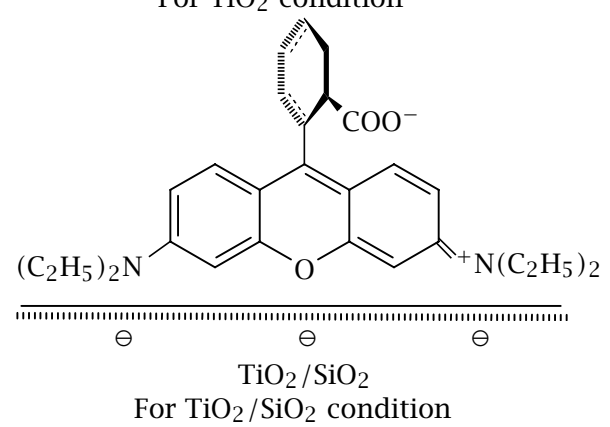

Scheme 1. Supposed adsorption modes of $\mathrm{RhB}$ on the surface of $\mathrm{TiO}_{2}$ and $\mathrm{TiO}_{2} / \mathrm{SiO}_{2}$ under the experimental conditions at $\mathrm{pH} 4.3$.

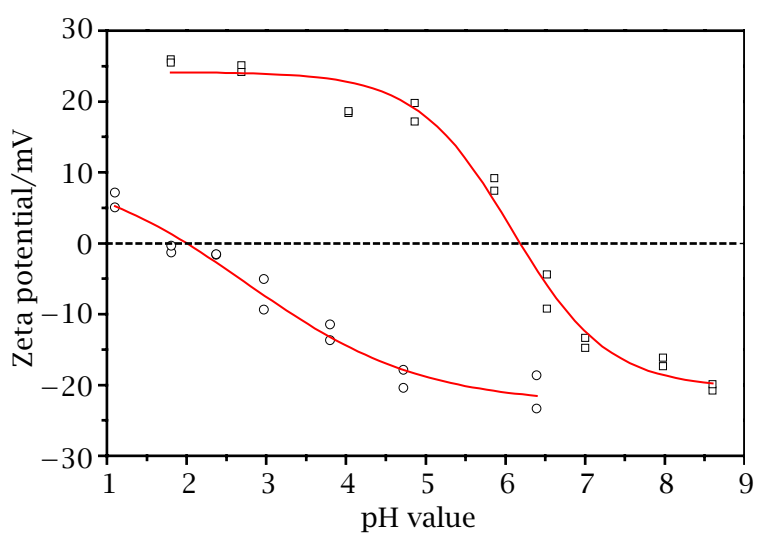

Figure 1. $\zeta$-potential of $(\square) \mathrm{TiO}_{2}(\mathrm{~S})$ and $(\circ) \mathrm{TiO}_{2} / \mathrm{SiO}_{2}$ in $10 \mathrm{mM} \mathrm{NaCl}$ aqueous dispersion.

Accordingly, due to the electrostatic interaction, adsorption of $\mathrm{RhB}$ molecules on the surface of $\mathrm{TiO}_{2} / \mathrm{SiO}_{2}$ is through positively charged diethylamino group, but in the case of net $\mathrm{TiO}_{2}$, $\mathrm{RhB}$ molecules tend to adsorb via the negatively charged carboxyl group. The speculation model of simple adsorption for the $\mathrm{RhB}$ molecules on the surface of $\mathrm{TiO}_{2}$ and $\mathrm{TiO}_{2} / \mathrm{SiO}_{2}$ under the experimental condition was illustrated in Scheme 1.

3.2. Degradation of $\mathrm{RhB}$ with $\mathrm{TiO}_{2}$ and $\mathrm{TiO}_{2} / \mathrm{SiO}_{2}$ photocatalyst under UV or visible irradiation. The adsorption of organic molecules on the surface of photocatalysts had been proved to influence greatly the photocatalytic degradation of the organics [5-7, 22]. $\mathrm{RhB}-\mathrm{TiO}_{2}$ and $\mathrm{RhB}-\mathrm{TiO}_{2} / \mathrm{SiO}_{2}$ systems were further investigated in this work to understand the influence of adsorption mode and intensity in the degradation of RhB.

RhB-P-25 system was also examined since P-25 is regards as a referential highly active photocatalyst in the literatures. The degradation of $\mathrm{RhB}$ in the presence of $\mathrm{P}-25, \mathrm{TiO}_{2}(\mathrm{~S})$ and $\mathrm{TiO}_{2} / \mathrm{SiO}_{2}$ under the visible light irradiation was depicted in the Figure 2. Although $\mathrm{RhB}$ was found very stable in the aqueous solution under the visible irradiation in the absence of $\mathrm{TiO}_{2}$, it was smoothly degraded by $\mathrm{P}-25$ and $\mathrm{TiO}_{2}(\mathrm{~S})$ accompanying with a slight hypsochromic shift of absorption bands. What's more, in the presence of $\mathrm{TiO}_{2} / \mathrm{SiO}_{2}$, degradation of $\mathrm{RhB}$ was greatly accelerated. The ratio among the UV-VIS absorption disappearance rate of $\mathrm{RhB}$ in the presence of $\mathrm{TiO}_{2}(\mathrm{~S}), \mathrm{P}-25$ and $\mathrm{TiO}_{2} / \mathrm{SiO}_{2}$ was $0.18 / 0.48 / 1$ at the beginning of the photodegradation reaction (in the first $60 \mathrm{~min}$ ) under the visible irradiation. One of the main reasons may be due to the much stronger adsorption of $\mathrm{RhB}$ on the surface of $\mathrm{TiO}_{2} / \mathrm{SiO}_{2}$ than that on the surface of $\mathrm{TiO}_{2}(\mathrm{~S})$. Under the experimental condition, about $43.2 \%$ of the $\mathrm{RhB}$ adsorbed on the surface of $\mathrm{TiO}_{2} / \mathrm{SiO}_{2}$ while only $8.4 \%$ (and 3.5\%) of $\mathrm{RhB}$ adsorbed on that of P-25 (and $\mathrm{TiO}_{2}(\mathrm{~S})$ ). Moreover, the reacted solution of $\mathrm{RhB}$ exhibited a much more 

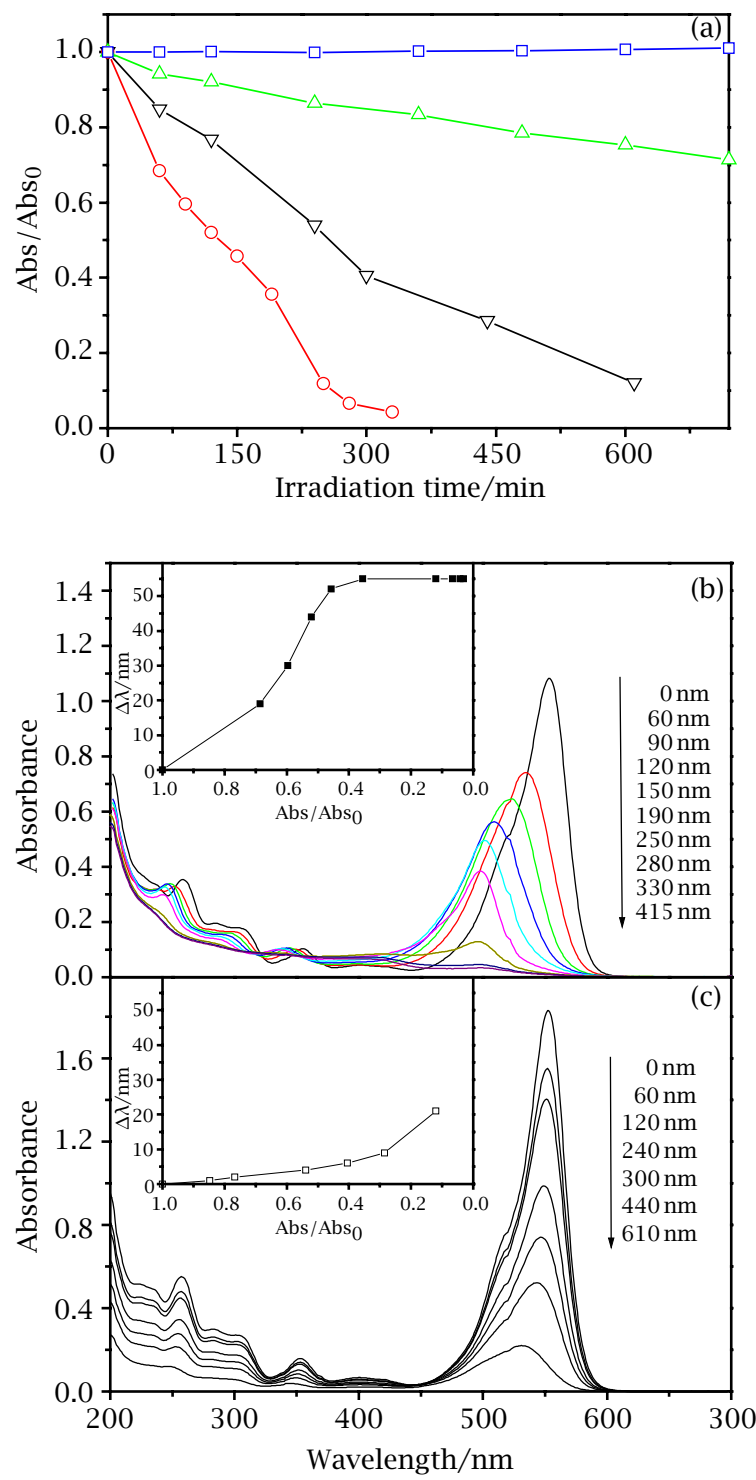

Figure 2. (a) Photodegradation of $\mathrm{RhB}$ in the presence of various kinds of photocatalysts in the aqueous dispersion under visible light irradiation $(\mathrm{pH}=4.3) .(\nabla) \mathrm{P}-25$, $(\Delta) \mathrm{TiO}_{2}(\mathrm{~S}),(\circ) \mathrm{TiO}_{2} / \mathrm{SiO}_{2}$ and $(\square)$ control reaction without photocatalyst. (b) Temporal spectral changes of $\mathrm{RhB}$ in aqueous $\mathrm{TiO}_{2} / \mathrm{SiO}_{2}$ dispersion under visible irradiation. Inset shows the hypsochromic shifts of RhB corresponding to the remainder max absorption in the visible region. (c) Temporal spectral changes of $\mathrm{RhB}$ in aqueous $\mathrm{P}-25$ dispersion under visible irradiation. Inset shows the hypsochromic shifts of RhB corresponding to the remainder max absorption in the visible region.

evident hypsochromic shift of absorption bands (Figure $2 \mathrm{~b}$ ) than that in the present of net $\mathrm{TiO}_{2}$ (Figure 2c). While the RhB solution left the $30 \%$ of the original absorbence, there were $55 \mathrm{~nm}$ hypsochromic shift for the $\mathrm{RhB}-\mathrm{TiO}_{2} / \mathrm{SiO}_{2}$ case and only $9 \mathrm{~nm}$ hypsochromic shift for the RhB-P-25 case, which strongly suggested that differences were existed between two systems.

HPLC spectrum was then employed to further study the difference in these two systems by analysis of the photooxidation Intermediates. Figure 3 shows the HPLC spectral patterns for $\mathrm{RhB}$ and the degradation products in the presence of $\mathrm{TiO}_{2} / \mathrm{SiO}_{2}$ corresponding to Figure $2 \mathrm{~b}$. $\mathrm{RhB}$ was rapidly transformed into its' hypsochromic shift intermediates, which had a shorter wavelength absorption. Five main components which have peak absorption at $541 \mathrm{~nm}$ (product I, retention time: $7.87 \mathrm{~min}$ ), $525 \mathrm{~nm}$ (product II-A, retention time: $5.10 \mathrm{~min}$ ), $529 \mathrm{~nm}$ (product II-B, retention time: $4.67 \mathrm{~min}$ ), $514 \mathrm{~nm}$ (product III, retention time: $3.34 \mathrm{~min}$ ) and $502 \mathrm{~nm}$ (product IV, retention time: $2.56 \mathrm{~min}$ ) with $\mathrm{RhB}(556 \mathrm{~nm}, 12.75 \mathrm{~min}$ ) are evident at retention times lass then $18 \mathrm{~min}$. The UV-VIS spectra of these intermediates with RhB in the HPLC eluant were depicted in Figure 3c. Figure $3 b$ shows that these intermediates were produced one by one in I, II-A and II-B, III, IV order; and in kinetics, it seems as if every intermediates were transformed from the one just before itself. The hypsochromic effect of $\mathrm{RhB}$ was predominant because of the deethylation via visible light assisted photocatalysis. Similar phenomena during the photocatalytic process due to the dealkylation had been observed earlier: the photooxidative $\mathrm{N}$-deethylation of Sulforhodamine B in the Sulforhodamine B/DBS/P-25 system [19] under visible light irradiation and slightly $\mathrm{N}$-demethylation in the Methylene Blue/P-25 system under UV irradiation [23]. The degradation products of $\mathrm{RhB}$ were also analyzed by LC-MS technique for further confirming. The positive ion mode ESI mass spectra are shown in Figure 4. The molecule structure of these intermediates was then identified by LC-MS, HPLC combining with UV-VIS spectra. The main intermediates corresponding to the $\mathrm{m} / \mathrm{z}$ values are summarized in Table 1 . By identification of the intermediates confirmed the deethylation process was proceeded in the visible light irradiation $\mathrm{RhB}-\mathrm{TiO}_{2} / \mathrm{SiO}_{2}$ system: $\mathrm{RhB}$ molecule lost the ethyl groups step by step to transform to products DMRh (I), DRh (II-A), MMRh (II-B), MRh (III) and $\mathrm{Rh}$ (Rhodamine 110, IV) and the final mineralization was carried out till it had lost all four ethyl groups to transform Rhodamine 110. Besides these intermediates, some very weak signs at $\mathrm{m} / \mathrm{z} 431.2,403.2,375.2$, 347.2 also shown the generation of hydroxyl group substituted products (for details, see Scheme 3 ). The photocatalytic intermediates of $\mathrm{RhB}^{-\mathrm{TiO}_{2}}$ system under the visible light were also determined by HPLC. The amount of these five deethylation products was remarkably lowered, and moreover, many other intermediates were found in the HPLC spectra in this case which indicated that the deethylation process was no longer a main procedure in this condition.

The adsorption modes of $\mathrm{RhB}$ on the surface of $\mathrm{TiO}_{2}$ and $\mathrm{TiO}_{2} / \mathrm{SiO}_{2}$ greatly influence the photocatalytic 

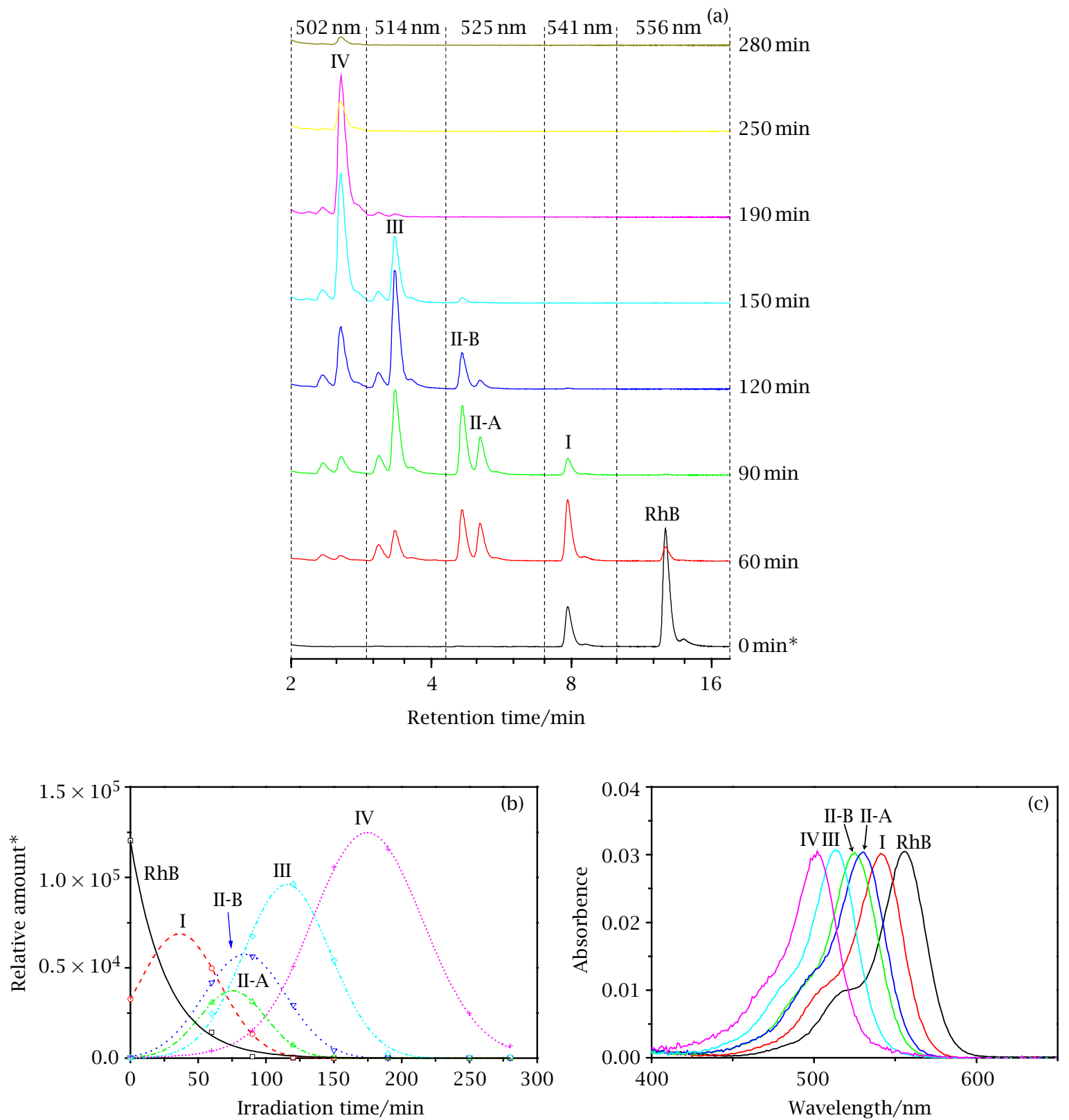

Figure 3. (a) HPLC spectra of $\mathrm{RhB}$ and its photooxidation intermediates in the presence of $\mathrm{TiO}_{2} / \mathrm{SiO}_{2}$ under visible light irradiation. The detected solution in the HPLC measurement was checked by UV-VIS detector and the absorbence was presented at $502 \mathrm{~nm}$ from 2 min to $2.9 \mathrm{~min}, 514 \mathrm{~nm}$ from $2.9 \mathrm{~min}$ to $4.3 \mathrm{~min}, 525 \mathrm{~nm}$ from $4.3 \mathrm{~min}$ to $7.0 \mathrm{~min}, 541 \mathrm{~nm}$ from 7.0 min to 10.0 min and $556 \mathrm{~nm}$ from 10.0 min to $17.5 \mathrm{~min}$ * Original RhB material is not pure and contains some amount of compound I. It had been checked that compound I can not be generated by the dark reaction in the presence of $\mathrm{TiO}_{2} / \mathrm{SiO}_{2}$. (b) The relative variation of $\mathrm{RhB}$ and its photooxidation intermediates corresponding to Figure 3(a). * The absolute amount of every compound was not fixed since we failed to collect all the samples and check the absorbence of each compound at experimental condition. (c) UV-VIS absorption of RhB and its photooxidation intermediates in the HPLC eluant by UV-VIS detector.

degradation mechanism of the RhB. RhB molecules adsorb on the surface of $\mathrm{TiO}_{2} / \mathrm{SiO}_{2}$ through diethylamino group, while they tend to adsorb via carboxyl group in the case of $\mathrm{RhB}-\mathrm{TiO}_{2}$. Therefore, active oxygen species predominantly attack the chromophore ring structure and induce the cleavage of the ring structure of $\mathrm{RhB}$ molecule in the $\mathrm{RhB}-\mathrm{TiO}_{2}$ case. And those in the $\mathrm{RhB}-\mathrm{TiO}_{2} / \mathrm{SiO}_{2}$ case mainly attack the 
Table 1. Identification of photooxidation intermediates of RhB by HPLC and LC-MS (positive ion mode ESI mass spectra).

\begin{tabular}{|c|c|c|c|c|c|}
\hline HPLC peaks & $\begin{array}{c}\text { Absorption } \\
\text { maximum (min) }\end{array}$ & $\begin{array}{l}\text { Retention } \\
\text { time (min) }\end{array}$ & Corresponding intermediares of $\mathrm{RhB}$ & $\mathrm{m} / \mathrm{z}$ & assigned substrates \\
\hline IV & 502 & 2.56 & rhodamine $110(\mathrm{Rh})$ & $\begin{array}{l}331.1 \\
353.1\end{array}$ & $\begin{array}{c}\mathrm{Rh}^{+} \\
\mathrm{Rh}-\mathrm{Na}^{+}\end{array}$ \\
\hline III & 514 & 3.34 & N-ethyl-rhodamine 110 (MRh) & $\begin{array}{l}359.1 \\
381.1\end{array}$ & $\begin{array}{c}\mathrm{MRh}^{+} \\
\mathrm{MRh}-\mathrm{Na}^{+}\end{array}$ \\
\hline II-B & 529 & 4.67 & N-ehyl-N'-ethyl-rhodamine 110 (MMRh) & $\begin{array}{l}387.1 \\
409.1\end{array}$ & $\begin{array}{c}\mathrm{MMRh}^{+} \\
\mathrm{MMRh}^{-\mathrm{Na}^{+}}\end{array}$ \\
\hline II-A & 525 & 5.10 & N,N-diethyl-rhodamine 110 (DRh) & $\begin{array}{l}387.1 \\
409.1\end{array}$ & $\begin{array}{c}\mathrm{DRh}^{+} \\
\text {DRh-Na }\end{array}$ \\
\hline I & 541 & 7.87 & N,N-diehyl-N'-ethyl-rhodamine 110 (DMRh) & $\begin{array}{l}415.1 \\
437.1\end{array}$ & $\begin{array}{c}\text { DMRh }^{+} \\
\text {DMRh-Na }\end{array}$ \\
\hline $\mathrm{RhB}$ & 556 & 12.75 & Rhodamine B (RhB) & $\begin{array}{l}443.1 \\
465.1\end{array}$ & $\begin{array}{c}\mathrm{RhB}^{+} \\
\mathrm{RhB}^{-\mathrm{Na}^{+}}\end{array}$ \\
\hline
\end{tabular}

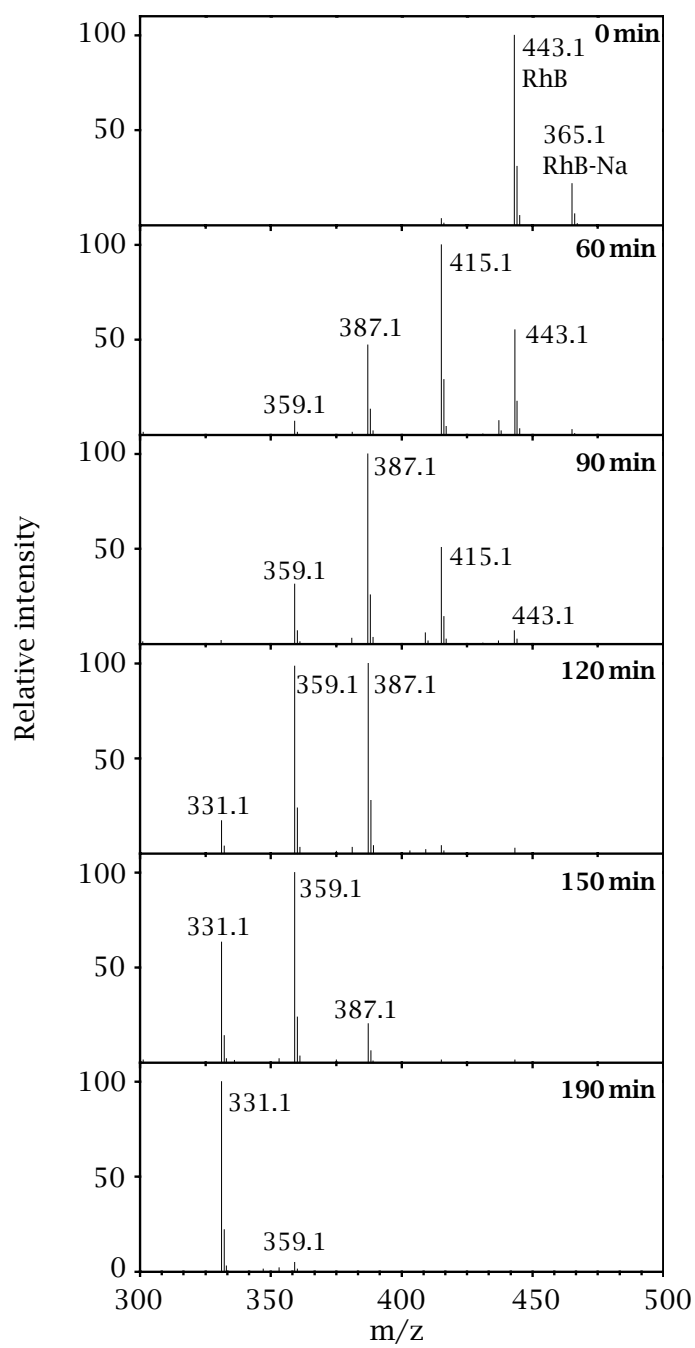

Figure 4. Positive ion ESI mass spectra in the photooxidation of $\mathrm{RhB}$ intermediates in the presence of $\mathrm{TiO}_{2} / \mathrm{SiO}_{2}$ under visible light irradiation.

auxochromic groups and induce the deethylation of the alkylamine group as shown in Scheme 3 below. The maximum molar extinction coefficient of Rodhamine
$\mathrm{B}$ is $106,000 \mathrm{~L} / \mathrm{mole} \mathrm{cm}$ at $545 \mathrm{~nm}$ [24] and that of Rhodamine 110 is $69000 \mathrm{~L} / \mathrm{mole} \mathrm{cm}$ at $498 \mathrm{~nm}$ [25] in methanol solution, which implies that the yield of Rhodamine 110 from RhB at 190 min was about 55\% (suppose the ratio of maximum molar extinction coefficient between $\mathrm{RhB}$ and Rhodamine 110 in aqueous solution nearly equal to that in methanol solution) and the average yield of every deethylation step was about $86 \%$. Considering Rhodamine 110 had been also degraded much before 190 min (especially in the 150-190 min region where rhodamine 110 was the main component in the solution) as shown in Figure $3 \mathrm{~b}$, the yield of the deethylation must be much higher than the evaluated value.

The same phenomena were also found in the $\mathrm{RhB}$ degradation under UV irradiation (see Figure 5), although the deethylation process was somewhat depressed. The wavelength shift of the RhB solution at the point where the solution remained $10 \%$ of the original absorbence shows the difference between two systems: $32 \mathrm{~nm}$ hypsochromic shift for the $\mathrm{RhB}-\mathrm{TiO}_{2} / \mathrm{SiO}_{2}$ case and $11 \mathrm{~nm}(13 \mathrm{~nm})$ hypsochromic shift for the RhB-P$25\left(\mathrm{RhB}^{-\mathrm{TiO}_{2}}(\mathrm{~S})\right)$ case as Figure $5 \mathrm{~b}$ shown. In comparison with that under the visible light irradiation, the degradation rate and the deethylation extent of $\mathrm{RhB}$ are much different under the UV irradiation. These differences could be due to the difference of the active oxygen species generation mechanism between these two cases [1-7]. Under the visible irradiation, only $\mathrm{RhB}$ (or its deethylation products) can absorb the photons, then the excited RhB molecule transfers the LUMO electron to the conductive band of $\mathrm{TiO}_{2}$, where the conductive electron reacts with preadsorbed oxygen molecules to produce active oxygen species. Thus, in this case, the adsorption of SRB is very important since it influences the electron injecting process from the excited $\mathrm{RhB}$ to $\mathrm{TiO}_{2}$. Under UV irradiation, $\mathrm{TiO}_{2}$ itself absorbs the photons and then directly react with $\mathrm{H}_{2} \mathrm{O}, \mathrm{O}_{2}$ and ${ }^{-} \mathrm{OH}$ group to produce active oxygen species. The adsorption of $\mathrm{RhB}$ is relative unimportant comparing with that under the visible irradiation since $\mathrm{TiO}_{2}$ can produce active 


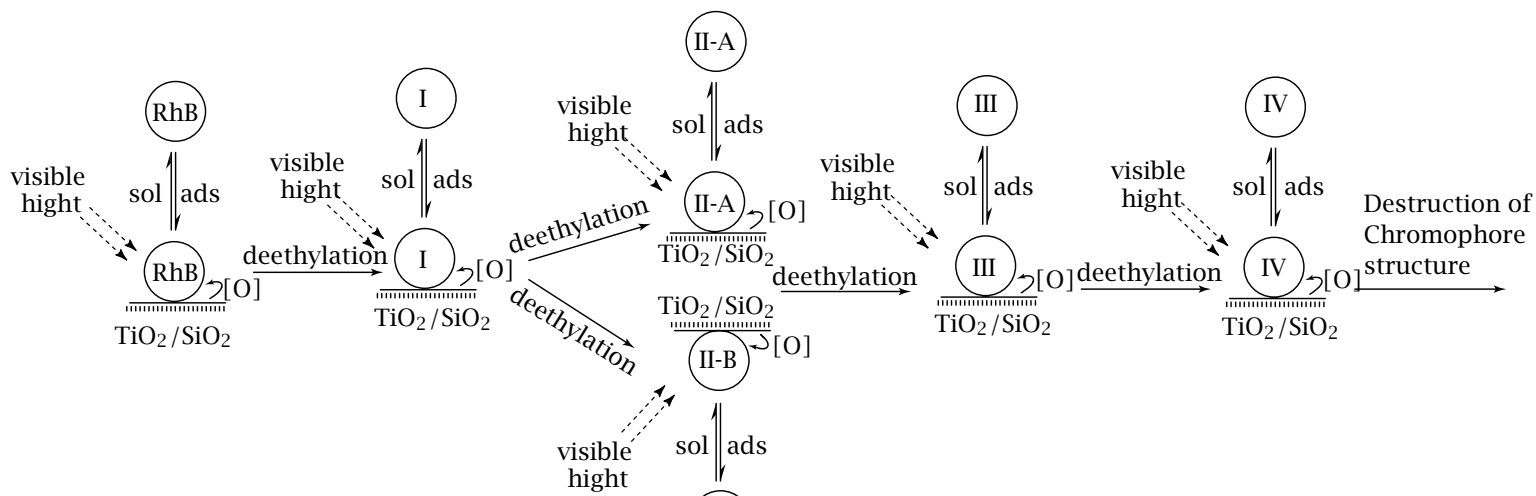

[O] means active oxygen species

(II-B)

Scheme 2. Stepwise deethylation process and the dynamic equilibrium of $\mathrm{RhB}$ and its deethylation intermediates species between the surface of $\mathrm{TiO}_{2} / \mathrm{SiO}_{2}$ and bulk solution in the photocatalytic oxidation of $\mathrm{RhB}$.
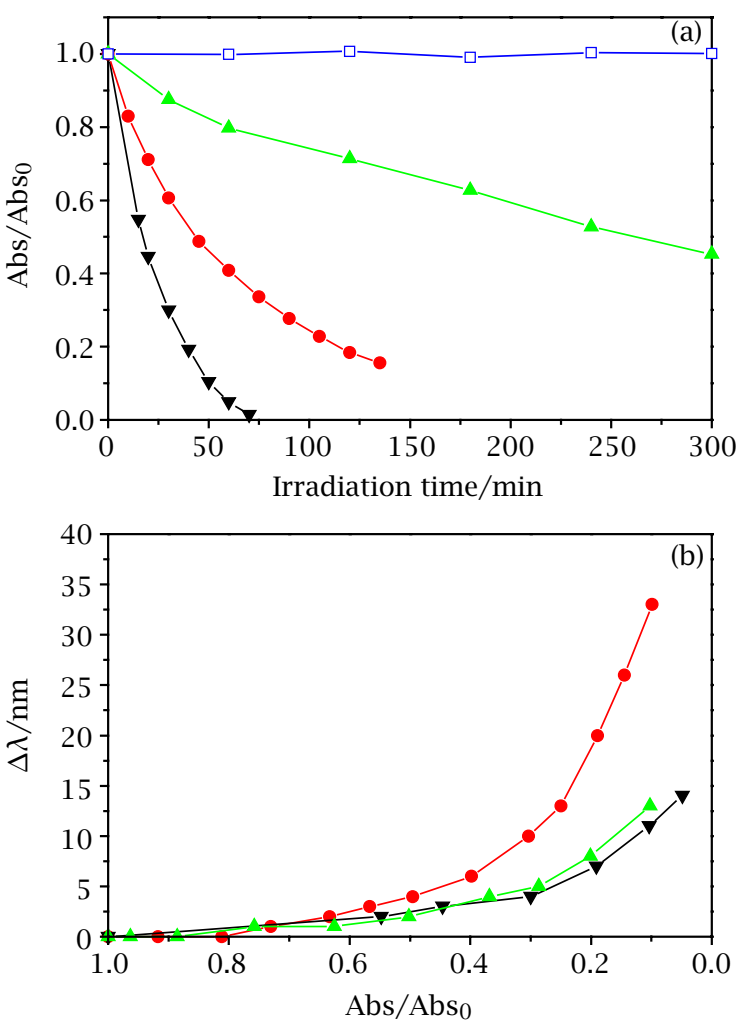

Figure 5. (a) Photodegradation of $R h B$ in the presence of various kinds of photocatalysts in the aqueous dispersion under UV irradiation. (b) Hypsochromic shift of RhB corresponding to the remainder max absorption in the visible region. $(\mathrm{pH}=4.3)$. ( $\mathbf{\nabla}) \mathrm{P}-25,(\boldsymbol{\Delta}) \mathrm{TiO}_{2}(S),(\bullet) \mathrm{TiO}_{2} / \mathrm{SiO}_{2}$ and $(\square)$ control reaction without photocatalyst.

oxygen species directly and independently. As shown in Figure 5, P-25 $\mathrm{TiO}_{2}$ exhibited a higher activity than $\mathrm{TiO}_{2} / \mathrm{SiO}_{2}$ under UV irradiation, which is entirely opposite to that under the visible irradiation.
3.3. Photooxidation pathway of RhB on the surface of $\mathrm{TiO}_{2}$ and $\mathrm{TiO}_{2} / \mathrm{SiO}_{2}$. Based on the probability of deethylation process of $\mathrm{RhB}$ in $\mathrm{RhB}-\mathrm{TiO}_{2} / \mathrm{SiO}_{2}$ case which was higher than $86 \%$ and an opposite direct degradation process of $\mathrm{RhB}$ in the case of $\mathrm{RhB}-\mathrm{TiO}_{2}$ under the visible light irradiation, the following three items were proposed: (1) Active oxygen species were mostly produced near the adsorption site of the $\mathrm{RhB}$ molecule (which was also the electron inject site from excited $\mathrm{RhB}$ molecule to $\mathrm{TiO}_{2}$ ); (2) Active oxygen species had strong advantages to attack the nearer organic groups, which were the adsorption groups of RhB here, thus we observed the ring cleavage for the carboxyl adsorption case and deethylation for the alkylamine adsorption case; (3) There is a fast dynamic adsorption/desorption equilibrium of RhB and its deethylated species between the solution bulk and the $\mathrm{TiO}_{2}$ particle surface during the photocatalytic deethylation process of $\mathrm{RhB}$ (as summarized in Scheme 2), since the deethylation of RhB was in an obviously stepwise manner (as shown in Figure 3b).

Under the UV irradiation, the sites to produce the active oxygen species are no longer restricted beside the adsorption site of RhB, which means that the attack of active oxygen species are less selectivity and the deethylation process are not so obvious as that under the visible irradiation. Even so, comparing with other portions of the molecule, the adsorption groups were relatively near to the surface of $\mathrm{TiO}_{2}$ where active oxygen species are generated, and still had a little bit priority to be attacked by active oxygen species. Thus, $\mathrm{RhB}$ also had a further deethylation on the surface of $\mathrm{TiO}_{2} / \mathrm{SiO}_{2}$ than on the surface of $\mathrm{TiO}_{2}$ based on the different adsorption mode under the UV irradiation as shown in Figure 5b.

Thus, in the carboxyl group adsorption mode (on the surface of $\mathrm{TiO}_{2}$ (s) and P-25), the chromophore structure of $\mathrm{RhB}$ was preferentially degraded directly with 


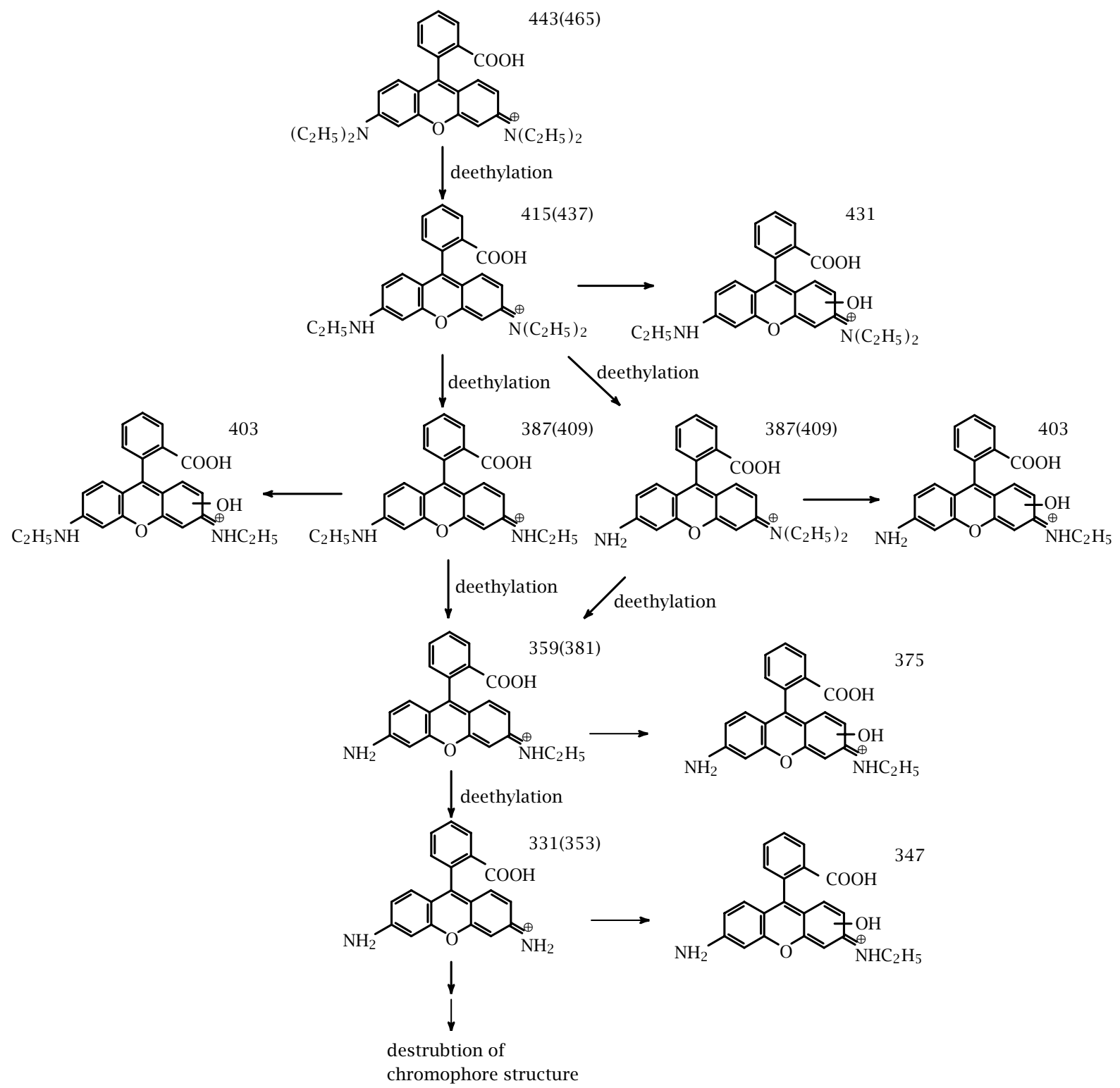

Scheme 3. Photooxidation pathway of $\mathrm{RhB}$ by $\mathrm{TiO}_{2} / \mathrm{SiO}_{2}$ under visible light irradiation.

active oxygen species under both UV and visible light irradiation. With respect to the diethylamino group adsorption mode (on the surface of $\mathrm{TiO}_{2} / \mathrm{SiO}_{2}$ ), $\mathrm{RhB}$ would prefer to be deethylated by the active oxygen species, especially under the visible light irradiation, in which those active oxygen species were mostly generated nearside the adsorption group. The photooxidation pathways of $\mathrm{RhB}$ by $\mathrm{TiO}_{2} / \mathrm{SiO}_{2}$ in the aqueous dispersions under visible light irradiation corresponding to the HPLC and LC-MS spectra are shown in Scheme 3.

\section{CONCLUSION}

Mingling $\mathrm{SiO}_{2}$ into $\mathrm{TiO}_{2}$ greatly lower the $\mathrm{pH}$ value of the isoelectric point of $\mathrm{TiO}_{2}$. $\mathrm{RhB}$ adsorbs on the surface of $\mathrm{TiO}_{2} / \mathrm{SiO}_{2}$ particles with diethylamino group while it adsorbs on the surface of $\mathrm{TiO}_{2}$ by carboxyl group at the weak acid conditions. In case of adsorption of a diethylamino group, $\mathrm{RhB}$ initially has a high selective stepwise deethylation process in which the various deethylated intermediate species have an adsorption/desorption equilibrium between $\mathrm{TiO}_{2} / \mathrm{SiO}_{2}$ surface and bulk solution before the destruction of the chromophore structure under visible light irradiation. The results confirm that visible light-assisted photocatalytic degradation proceeds on the surface of $\mathrm{TiO}_{2}$ (and $\mathrm{TiO}_{2} / \mathrm{SiO}_{2}$ ) particles rather than in the bulk and active oxygen species much prefer to attack the positions near the surface of $\mathrm{TiO}_{2}$. This work provides a possibility that we can utilize oxides to modify the surface characteristic of 
$\mathrm{TiO}_{2}$ to adsorb effectively the special colored organic molecules in selective mode to control the molecular selective modification or deeply extent photooxidation.

\section{ACKNOWLEDGEMENT}

Studies carried out in Tokyo are sponsored by the Frontier Research Foundation as well as Grants-in-Aid for Science Research (C) (No. 10640569; to HH) from the Japanese Ministry of Education, Sports, Culture, Science and Technology, whereas the research carried out in Beijing is supported by the National Natural Science Foundation of China (No. 29677019 and No. 29725715; to JZ) and the Foundation of the Chinese Academy of Sciences.

\section{REFERENCES}

[1] M. A. Fox and M. T. Dulay, Chem. Rev. 93 (1993), 341.

[2] A. L. Linsebigler, G. Lu, and J. T. Yates, Chem. Rev. 95 (1995), 735.

[3] S. Horikoshi, N. Watanabe, M. Mukae, H. Hidaka, and N. Serpone, New J. Chem. 25 (2001), 999.

[4] P. Qu, J. Zhao, T. Shen, and H. Hidaka, Colloids Surf. A 138 (1998), 39.

[5] J. Zhao, T. Wu, K. Wu, K. Okikawa, H. Hidaka, and N. Serpone, Environ. Sci. Technol. 32 (1998), 2394.

[6] G. Liu, T. Wu, J. Zhao, H. Hidaka, and N. Serpone, Environ. Sci. Technol. 33 (1999), 2081.

[7] T. Wu, G. Liu, J. Zhao, H. Hidaka, and N. Serpone, J. Phys. Chem. B 103 (1999), 4862.

[8] C. Nasr, K. Vinodgopal, L. Fisher, S. Hotchandani, A. K. Chattopadhya, and P. V. Kamat, J. Phys. Chem. 100 (1996), 8436.
[9] Y. Cho, W. Choi, C. Lee, T. Hyeon, and H. Lee, Environ. Sci. Tchnol. 35 (2001), 966.

[10] C. Lettmann, K. Hildenbrand, H. Kisch, W. Macyk, and W. F. Maier, Appl. Catal. B 32 (2001), 215.

[11] R. Asahi, T. Morikawa, T. Ohwaki, K. Aoki, and Y. Taga, Science 293 (2001), 269.

[12] B. O’Regan and M. Gratzel, Nature 353 (1991), 737.

[13] U. Bach, D. Lupo, P. Comte, J. E. Moser, F. Weissortel, J. Salbeck, H. Spreitzer, and M. Gratzel, Nature 395 (1998), 583.

[14] T. Torimoto, S. Ito, S. Kuwabata, and H. Yoneyama, Environ. Sci. Technol. 30 (1996), 1275.

[15] H. Tada, M. Akazawa, Y. Kubo, and S. Ito, J. Phys. Chem. B 102 (1998), 6360.

[16] Y. Xu, W. Zhang, and W. Liu, J. Photochem. Photobiol. A 122 (1999), 57.

[17] L. J. Alemany, M. A. Banares, E. Pardo, F. Martin, M. G. Fereres, and J. M. Blasco, Appl. Catal. B 13 (1997), 289.

[18] Y. Xu and C. H. Langford, J. Phys. Chem. B 101 (1997), 3115.

[19] G. Liu, X. Li, J. Zhao, H. Hidaka, and N. Serpone, Environ. Sci. Technol. 34 (2000), 3982.

[20] P. Qu, J. Zhao, T. Shen, H. Hidaka, and N. Serpone, J. Mol. Catal. A 129 (1998), 257.

[21] J. Zhao, H. Hidaka, A. Takamura, E. Pelizzetti, and N. Serpone, Langmuir 9 (1993), 1646.

[22] Y. Xu and C. H. Langford, Langmuir 17 (2001), 897.

[23] T. Zhang, T. Oyama, A. Aoshima, H. Hidaka, J. Zhao, and N. Serpone, J. Photochem. Photobiol. A 140 (2001), 163.

[24] H. Du, R. A. Fuh, J. Li, A. Corkan, and J. S. Lindsey, Photochem. Photobiol. 68 (1998), 141.

[25] S. A. Tuccio and F. C. Jr. Strome, Appl. Opt. 11 (1972), 64. 


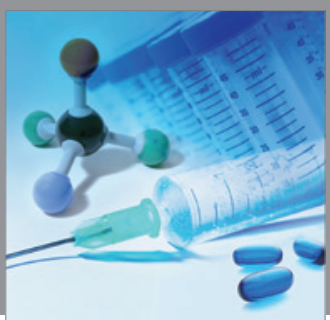

International Journal of

Medicinal Chemistry

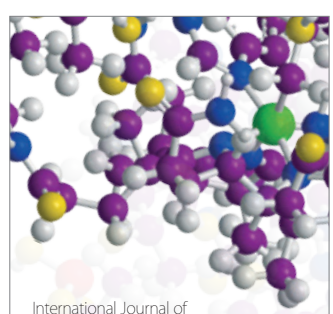

Carbohydrate Chemistry

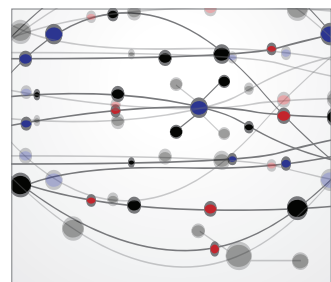

The Scientific World Journal
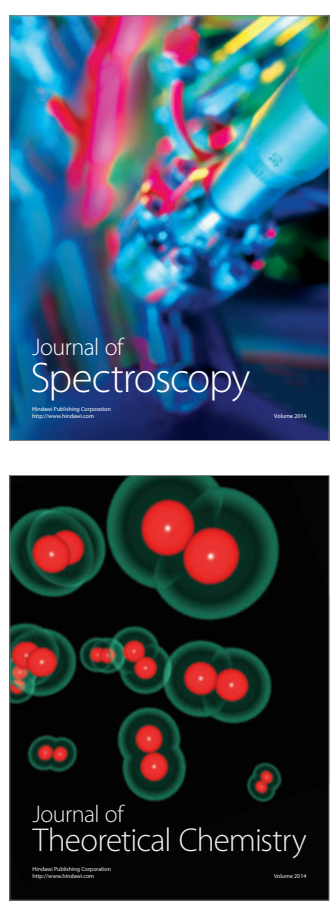
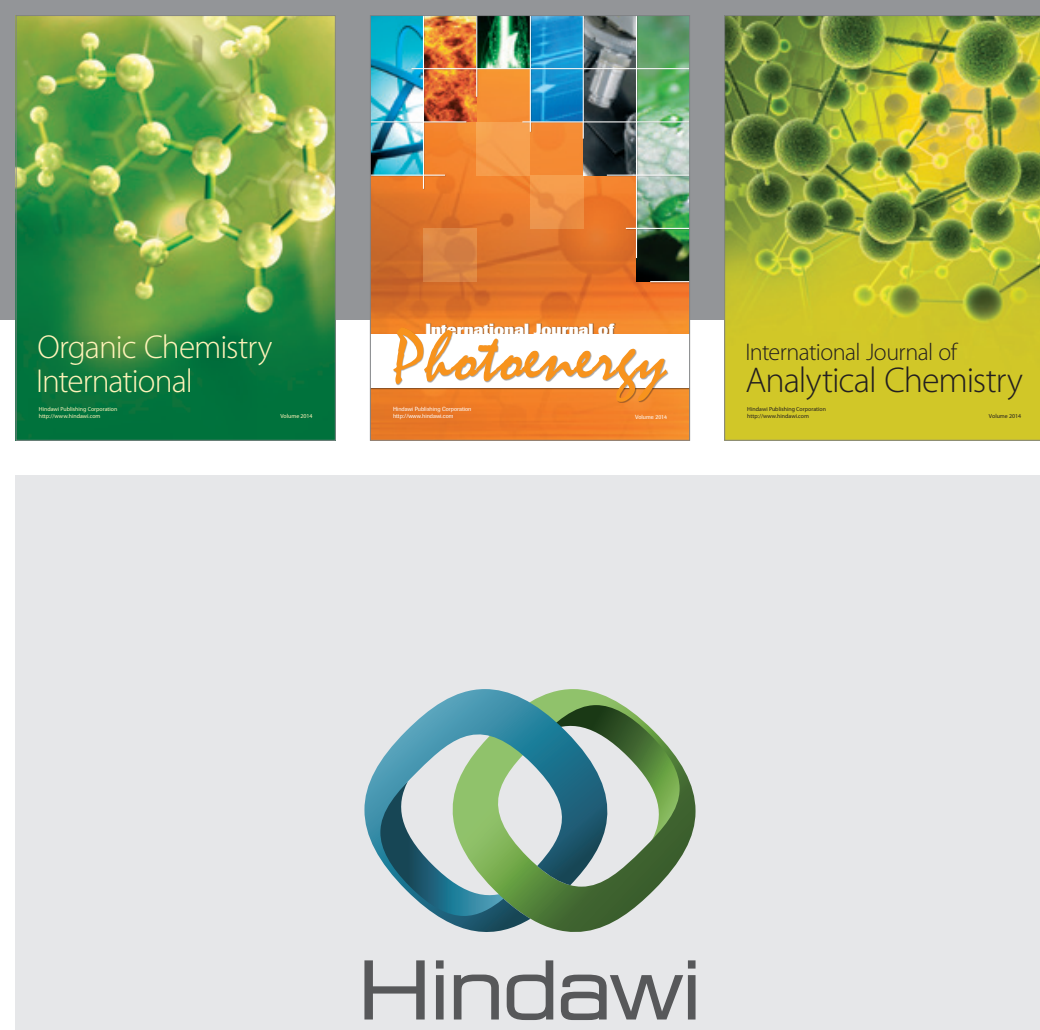

Submit your manuscripts at

http://www.hindawi.com
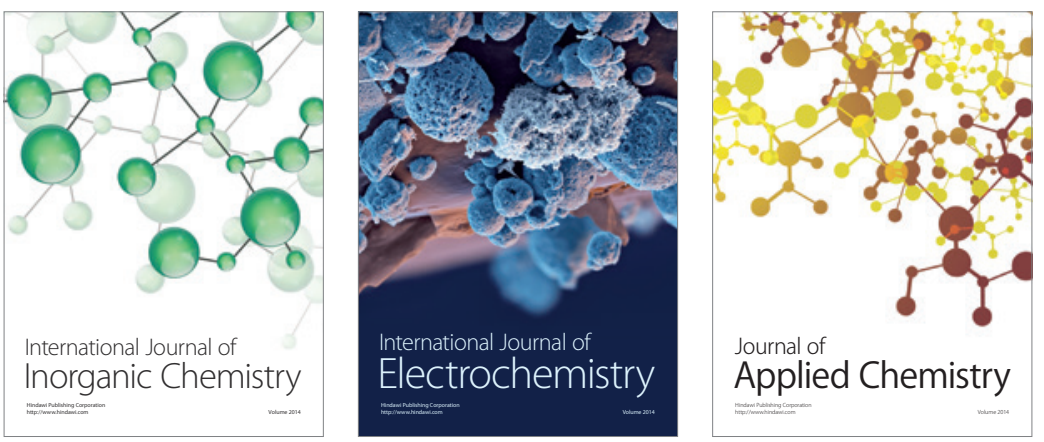

Journal of

Applied Chemistry
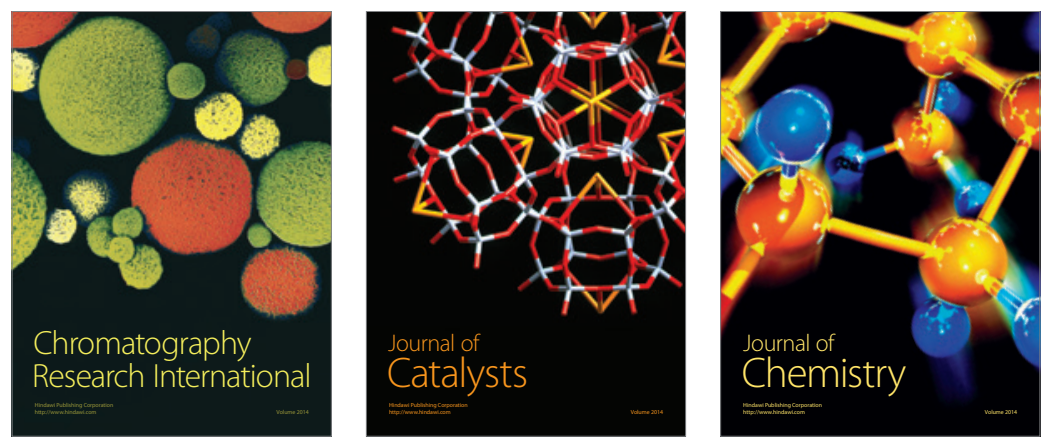
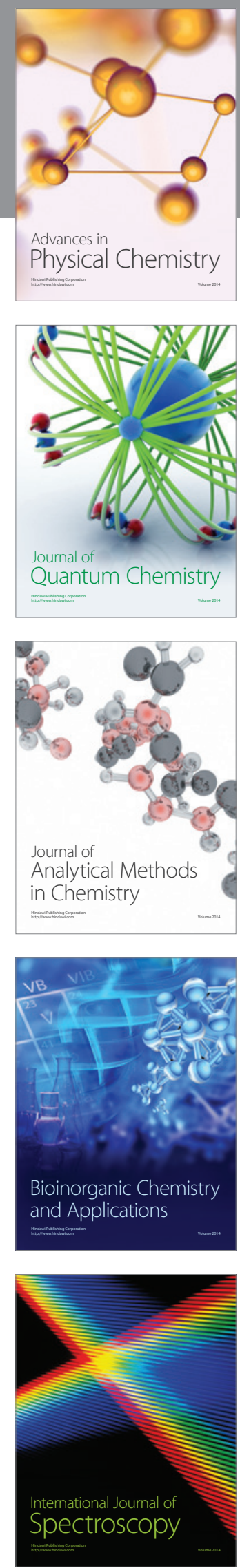